ARTICLE

\title{
Simultaneous Measurement of Radon and Thoron Released from Building Materials Used in Japan
}

\author{
Nabil M. HASSAN ${ }^{* 1,2,3}$, Masahiro HOSODA ${ }^{2}$, Kazuki IWAOKA $^{2}$, Atsuyuki SORIMACHI ${ }^{2}$, Miroslaw JANIK ${ }^{2}$, \\ Chutima KRANROD ${ }^{2}$, Sarata K. SAHOO ${ }^{2}$, Tetsuo ISHIKAWA ${ }^{2}$, Hidenori YONEHARA ${ }^{2}$, Masahiro FUKUSHI ${ }^{1}$, \\ Shinji TOKONAMI ${ }^{2}$ \\ ${ }^{1}$ School of Radiological Sciences, Tokyo Metropolitan University, 7-2-10 Higashioku, Arakawa-ku, Tokyo 116-8551, Japan \\ ${ }^{2}$ Research Centre for Radiation Protection, National Institute of Radiological Sciences, 4-9-1 Anagawa, Inage-ku, Chiba 263-8555, Japan \\ ${ }^{3}$ Department of Physics, University of Zagazig, Zagazig 44519, Egypt
}

\begin{abstract}
Common building materials used in constructing dwellings are a major source of radon and thoron gases emanation into the indoor environment. Concentrations of the radionuclides ${ }^{226} \mathrm{Ra}$ and ${ }^{232} \mathrm{Th}$ and radon/thoron exhalation rates are important parameters for characterizing radon and thoron sources in building materials and comparing the relative contribution of different materials to the total radiation dose. In the present study, concentrations of the radionuclides ${ }^{226} \mathrm{Ra},{ }^{232} \mathrm{Th}$ and ${ }^{40} \mathrm{~K}$ in different kinds of granite used as building materials in Japan were determined by $\gamma$-ray spectroscopy, and a common hazard index, the radium equivalent index, was evaluated on the basis of those results. Exhalation rates of radon and thoron were measured by using an accumulation chamber equipped with a solid-state alpha particle detector. The influence of chamber leakage and back diffusion time decay constants on radon exhalation rate was also estimated, and the correlations between radon/thoron exhalation rates and their parent nuclide (radium/thorium) concentrations were examined.
\end{abstract}

KEYWORDS: radionuclide concentration, radon, thoron, exhalation rate, radiation hazard, building materials, Japan

\section{Introduction}

Radon $\left({ }^{222} \mathrm{Rn}\right)$ and thoron $\left({ }^{220} \mathrm{Rn}\right)$ gases as well as their corresponding progenies are present in all dwellings owing to the presence of their parent nuclides (uranium and thorium) in various building materials. These radioactive gases contribute more than $50 \%$ of the radiation dose received by individuals from natural radiation sources. ${ }^{1)}$ This substantial level of radiological risk of radon and thoron implies that the role of different materials that might be a source of radon or thoron in workplace or residential construction should be evaluated and that radon and thoron transport from those materials to indoor air should be examined. The solution of radon isotope problems is therefore both scientifically challenging and potentially relevant to the quality of human life.

It is well known that radiation exposure can be external or internal and that most of the dose due to building materials in dwellings is caused by $\gamma$-rays and $\alpha$-particles emitted from radionuclides of the uranium $\left({ }^{238} \mathrm{U}\right)$ and thorium $\left({ }^{232} \mathrm{Th}\right)$ decay series as well as from the potassium radionuclide ${ }^{40} \mathrm{~K}$. The concentration of these radionuclides can be measured by high-resolution $\gamma$-ray spectroscopy. External exposure occurs directly by exposure to $\gamma$-rays, whereas internal exposure to $\alpha$-particles results from inhalation of radon, thoron and their progenies. Consequently, the $\alpha$-particle dose is delivered directly to the bronchial tissue, increasing radiogenic lung cancer. $^{2)}$

*Corresponding Author, E-mail: hassan@fml.nirs.go.jp

(c) Atomic Energy Society of Japan
Radon $\left({ }^{222} \mathrm{Rn}: T_{1 / 2}, 3.82 \mathrm{~d}\right)$ and thoron $\left({ }^{220} \mathrm{Rn}: T_{1 / 2}, 56 \mathrm{~s}\right)$ are radioactive gases produced by the decay of ${ }^{226} \mathrm{Ra}$ and ${ }^{224} \mathrm{Ra}$, which are themselves decay products of ${ }^{238} \mathrm{U}$ and ${ }^{232} \mathrm{Th}$, respectively. Radon and thoron are generated within solid grains of materials, and a fraction of the generated gases escapes into pore spaces among the solid grains, which allows them to migrate, or be exhaled, from their generation site in rocks, soils, or building materials to atmospheric air before undergoing radioactive decay. The exhalation rate is the amount of activity released per unit of surface area per unit time. Materials can be classified according to the potential risk of radon/thoron exposure by evaluating the exhalation rate and related parameters. ${ }^{3,4)}$

The contribution of building materials to indoor radon and thoron concentrations is usually low. However, certain materials of natural origin such as granite, concrete and by-products of different industries account for an unusually large fraction of the total radon and thoron concentrations in the indoor environment. Japan uses various kinds of building materials, including granite, marble and other rocks, for constructing modern houses and as cladding on public buildings. Therefore, we measured concentrations of the radionuclides ${ }^{238} \mathrm{U}\left({ }^{226} \mathrm{Ra}\right),{ }^{232} \mathrm{Th}$, and ${ }^{40} \mathrm{~K}$ in several kinds of granite commonly used as building materials in Japan. In addition, we estimated several parameters, including the radium equivalent index and the radon/thoron exhalation rate, to evaluate the radiological risk associated with those building materials. 


\section{Experiments}

\section{Sample Preparation}

Different kinds of granite (building materials), from Japan, China, Finland, India, Brazil, Portugal and Norway, were collected from several commercial Japanese companies. Samples of each material were dried in a temperature controlled furnace (oven) at $110{ }^{\circ} \mathrm{C}$ for more than $24 \mathrm{~h}$ to ensure complete removal of moisture and cooled to room temperature in a desiccator. The dried samples were used for determination of ${ }^{226} \mathrm{Ra},{ }^{232} \mathrm{Th}$, and ${ }^{40} \mathrm{~K}$ concentrations and of radon/thoron exhalation rates, which were estimated by using an accumulation chamber and a solid-state alpha detector (RAD7, Durridge Co. Inc., Bedford, MA, USA).

\section{Measurement of Radionuclide Concentrations}

Samples were crushed to fine powder and then sieved and placed in cylindrical polypropylene containers (diameter $=$ $48 \mathrm{~mm}$; height $=58 \mathrm{~mm}$ ). The sealed samples were left for more than 30 days to achieve radioactive secular equilibrium between ${ }^{226} \mathrm{Ra} /{ }^{224} \mathrm{Ra}$ and ${ }^{222} \mathrm{Rn} /{ }^{220} \mathrm{Rn}$. The concentrations of ${ }^{226} \mathrm{Ra},{ }^{232} \mathrm{Th}$, and ${ }^{40} \mathrm{~K}$ were then measured with a high-purity germanium (HPGe) detector (GEM-100210, EG \& G ORTEC, Oak Ridge, TN, USA). The counting time was pre-set to $80,000 \mathrm{~s} .{ }^{226} \mathrm{Ra}$ was estimated from the $609.3-\mathrm{keV}$ (absolute emission probability of a $\gamma$-ray, ${ }^{5}{ }^{46.1 \%}$ ) $\gamma$-peak of ${ }^{214} \mathrm{Bi}$ and the $351.9-\mathrm{keV}(37.6 \%) \gamma$-peak of ${ }^{214} \mathrm{~Pb}$. ${ }^{232} \mathrm{Th}$ was estimated from the $911.2-\mathrm{keV}(27 \%) \gamma$-peak of ${ }^{228} \mathrm{Ac}$, and ${ }^{40} \mathrm{~K}$ from the $1461-\mathrm{keV}(10.7 \%) \gamma$-peak of ${ }^{40} \mathrm{~K}$ itself.

\section{Measurement of Radon and Thoron Parameters}

The accumulation method of exhalation rate measurement has two disadvantages: leakage and back diffusion time decay constants. These parameters affect the precision of the estimation radon/thoron exhalation rates. Therefore, we studied the influence of the leakage and back diffusion decay time constants. A small polyvinyl chloride vessel (volume, 9.26 L) was used as the radon/thoron accumulation chamber, which was purged with nitrogen gas to reduce the background radon/thoron concentration to zero before the sample was placed within. In this system, the accumulation chamber is connected to the RAD7 detector by vinyl tubing (Fig. 1), with a gas-drying unit filled with a desiccant $\left(\mathrm{CaSO}_{4}\right.$ with $3 \% \mathrm{CoCl}_{2}$ as an indicator) between them, to maintain the relative humidity at $<10 \%$ within the measurement system. The system is a closed loop in which the gas circulates continuously. The experiment was performed at a relative humidity of 10\%, 18-22 ${ }^{\circ} \mathrm{C}$, and normal room atmospheric pressure.

After the sample is placed in the accumulation chamber, air containing radon/thoron gas is drawn into the inner chamber of the RAD7 instrument, after passing through the desiccant and an inline filter, and then returned to the accumulation chamber. While within the RAD7 inner chamber, radon/thoron gases generate detectable $\alpha$-particle emitting progenies, particularly polonium isotopes, which are collected onto the solid-state detector by high voltage $(2500 \mathrm{~V})$, applied between the inner chamber walls and the detector. The detector converts $\alpha$-particle energy to an

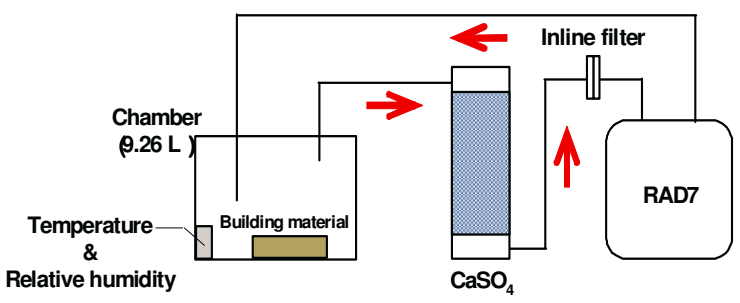

Fig. 1 Schematic diagram of the experimental system

electrical signal by an $\alpha$-particle spectrometry technique that allows radon and thoron progenies to be distinguished; thus, it can measure radon and thoron concentrations precisely.

When a sample is put into the accumulation chamber, the concentration of radon/thoron exhaled from the sample increases exponentially until radioactive secular equilibrium is reached. The exhalation rate $\left(E_{0}\right)$ from the sample can be calculated with Eq. (1). ${ }^{6}$

$E_{0}=\frac{C \times \lambda V}{S\left(1-e^{-\lambda t}\right)}$

where $C$ is the net concentration (exhaled radon/thoron less the background concentration) at accumulation time $t(\mathrm{~Bq}$ $\left.\mathrm{m}^{-3}\right), \lambda$ is the decay constant $\left(\mathrm{s}^{-1}\right), V$ is the effective air volume $\left(\mathrm{m}^{3}\right)$, and $S$ is the sample's surface area $\left(\mathrm{m}^{2}\right)$. This above equation is valid only if there is no leakage of radon/thoron into or out of the chamber, and if the activity concentration of gases in the accumulation chamber is always less than that in the pore space of the material (i.e., no back diffusion effect). We can neglect the back diffusion effect if the effective air volume of the chamber at least 10 times the pore space volume of the sample. ${ }^{7)}$ In general, both leakage and back diffusion occur with the accumulation method; thus, the decay constant in Eq. (1) must be replaced with the effective time decay constant $\left(\lambda_{\mathrm{eff}}\right)$.

$\lambda_{\text {eff }}=\lambda+\lambda_{1}+\lambda_{\mathrm{b}}$

where $\lambda_{1}$ and $\lambda_{\mathrm{b}}$ are the leakage and back diffusion time decay constants $\left(\mathrm{s}^{-1}\right)$, respectively. Therefore, Eq. (3) was used to calculate the exhalation rate.

$E_{0}=\frac{C \times \lambda_{\text {eff }} V}{S\left(1-e^{-\lambda_{\text {eff }} t}\right)}$

The value of the leakage time decay constant is estimated by injecting an accurately measured quantity of radon into the accumulation chamber and measuring its natural decay experimentally and also calculating its theoretical value (assuming no leakage). Then, the leakage time decay constant can be estimated with Eq. (4). ${ }^{6,8)}$

$\lambda_{1}=\left(\frac{M_{\mathrm{f}}-M_{1}}{C_{\mathrm{b}}-C_{0}}\right)$

where $M_{\mathrm{f}}$ is the initial slope of the theoretical radon decay curve $\left(\mathrm{Bq} \mathrm{m} \mathrm{m}^{-3} \mathrm{~s}^{-1}\right), M_{1}$ is the initial slope of the experimental radon decay curve $\left(\mathrm{Bq} \mathrm{m} \mathrm{m}^{-3}\right), C_{\mathrm{b}}$ is the initial radon concentration inside the chamber $\left(\mathrm{Bq} \mathrm{m}^{-3}\right)$, and $C_{0}$ is the background radon concentration of the whole system (Bq 
$\mathrm{m}^{-3}$ ). The back diffusion time decay constant is calculated with Eq. (5). ${ }^{6,8)}$

$\lambda_{\mathrm{b}}=\frac{M_{\mathrm{e}}}{C_{\mathrm{eq}}}-\left(\lambda+\lambda_{1}\right)$

where $M_{\mathrm{e}}$ is the initial slope of the radon build-up curve inside the chamber $\left(\mathrm{Bq} \mathrm{m} \mathrm{m}^{-3} \mathrm{~s}^{-1}\right)$ and $C_{\mathrm{eq}}$ is the equilibrium radon concentration.

\section{Results and Discussion}

Concentrations of the radionuclides ${ }^{226} \mathrm{Ra},{ }^{232} \mathrm{Th}$, and ${ }^{40} \mathrm{~K}$ in the selected granite samples measured with the HPGe detector are shown in Table $\mathbf{1 .}$

Table 1 Radionuclide concentrations in various kinds of granite

\begin{tabular}{llllll}
\hline \multirow{2}{*}{ Color } & Country & ID & \multicolumn{3}{c}{ Concentration $\left(\mathrm{Bq} \mathrm{kg}^{-1}\right)$} \\
\cline { 3 - 5 } Gray & Japan & JGG-1 & $34 \pm 1$ & $52 \pm 2$ & $1098 \pm 12$ \\
Gray & Japan & JGG-2 & $44 \pm 1$ & $53 \pm 2$ & $1005 \pm 12$ \\
Gray & Japan & JGG-3 & $50 \pm 1$ & $50 \pm 2$ & $1200 \pm 13$ \\
Brown & Japan & JBG-1 & $65 \pm 1$ & $86 \pm 2$ & $1143 \pm 12$ \\
Brown & Japan & JBG-2 & $73 \pm 1$ & $96 \pm 2$ & $1125 \pm 12$ \\
Gray & China & CGG-1 & $113 \pm 2$ & $150 \pm 3$ & $1412 \pm 17$ \\
Brown & China & CBG-1 & $99 \pm 2$ & $135 \pm 3$ & $1357 \pm 17$ \\
Brown & China & CBG-2 & $149 \pm 2$ & $225 \pm 4$ & $1420 \pm 18$ \\
Red & China & CRG-1 & $40 \pm 1$ & $61 \pm 2$ & $1274 \pm 13$ \\
Red & India & IRG-1 & $253 \pm 2$ & $234 \pm 4$ & $1307 \pm 17$ \\
Gray & Norway & NGG-1 & $250 \pm 4$ & $250 \pm 4$ & $1462 \pm 18$ \\
Gray & Portugal & PGG-1 & $120 \pm 1$ & $125 \pm 3$ & $1798 \pm 15$ \\
Brown & Finland & FBG-1 & $106 \pm 1$ & $165 \pm 3$ & $1530 \pm 14$ \\
Red & Finland & FRG-1 & $221 \pm 2$ & $373 \pm 5$ & $1594 \pm 19$ \\
Red & Brazil & BRG-1 & $98 \pm 2$ & $189 \pm 3$ & $1260 \pm 17$ \\
\hline \multicolumn{2}{|c}{ Average (mean \pm SD) } & $114 \pm 74$ & $150 \pm 92$ & $1332 \pm 211$ \\
\hline
\end{tabular}

The mean (range) radionuclide concentrations of ${ }^{226} \mathrm{Ra}$, ${ }^{232} \mathrm{Th}$, and ${ }^{40} \mathrm{~K}$ in the samples were $114 \pm 74 \mathrm{~Bq} \mathrm{~kg}^{-1}$ (34-253); $150 \pm 92 \mathrm{~Bq} \mathrm{~kg}^{-1}$ (50-373); and $1332 \pm 211 \mathrm{~Bq}$ $\mathrm{kg}^{-1}$ (1005-798), respectively. Most samples had radionuclide concentrations greater than the world average values, as reported elsewhere (e.g., UNSCEAR ${ }^{1)}$ reported the following concentrations of radionuclides in building materials: ${ }^{226} \mathrm{Ra}, 50 \mathrm{~Bq} \mathrm{~kg}^{-1}$; ${ }^{232} \mathrm{Th}, 50 \mathrm{~Bq} \mathrm{~kg}^{-1}$; and ${ }^{40} \mathrm{~K}, 500$ $\left.\mathrm{Bq} \mathrm{kg}^{-1}\right)$. Concentrations of ${ }^{226} \mathrm{Ra}$ in two Japanese granites (JGG-1 and JGG-2) and a Chinese granite (CRG-1) were less than the world average value, whereas concentrations of ${ }^{222} \mathrm{Ra},{ }^{232} \mathrm{Th}$, and ${ }^{40} \mathrm{~K}$ in the other samples exceeded world average values.

The radium equivalent index $\left(R a_{\mathrm{eq}}\right)$, calculated with Eq. (6), is commonly used to compare radionuclide concentrations $\left({ }^{226} \mathrm{Ra},{ }^{232} \mathrm{Th}\right.$, and $\left.{ }^{40} \mathrm{~K}\right)$ in materials.

$R a_{\mathrm{eq}}=A_{\mathrm{Ra}}+1.43 A_{\mathrm{Th}}+0.077 A_{\mathrm{K}}$

where $A_{\mathrm{Ra}}, A_{\mathrm{Th}}$, and $A_{\mathrm{K}}$ are the concentrations of ${ }^{226} \mathrm{Ra},{ }^{232} \mathrm{Th}$, and ${ }^{40} \mathrm{~K}$, respectively, in $\mathrm{Bq} \mathrm{kg}^{-1}$. The index was calculated on the basis of the estimation that $370 \mathrm{~Bq} \mathrm{~kg}^{-1}$ of ${ }^{226} \mathrm{Ra}, 259$ $\mathrm{Bq} \mathrm{kg}{ }^{-1}$ of ${ }^{232} \mathrm{Th}$, and $4810 \mathrm{~Bq} \mathrm{~kg}^{-1}$ of ${ }^{40} \mathrm{~K}$ all produce the same $\gamma$-ray dose rate. For safe use of building materials, ${ }^{1)}$ $R a_{\text {eq }}$ should be less than $370 \mathrm{~Bq} \mathrm{~kg}^{-1}$ to keep the external dose below $1.5 \mathrm{mSv} \mathrm{y}^{-1}$. Radium equivalent index of the samples varied from $193 \pm 5$ to $877 \pm 10 \mathrm{~Bq} \mathrm{~kg}^{-1}$ with a mean value of $431 \pm 209 \mathrm{~Bq} \mathrm{~kg}^{-1}$ (Table 2).

The index value of all but six (i.e., all five Japanese granite samples and the Chinese granite sample CRG-1) studied granite samples was higher than the recommended value $\left(370 \mathrm{~Bq} \mathrm{~kg}^{-1}\right)$. Therefore, we recommend that only these six granites be used for construction without regulation. The use of the other granites should be carefully regulated to reduce exposure to hazardous radiation released from them.

We also evaluated the leakage and back diffusion time decay constants. The leakage time decay constant, $0.34 \times 10^{-6}$ $\mathrm{s}^{-1}$, a characteristic of the accumulation chamber, is the probability of loss of radon/thoron atoms through leakage per unit time. The back diffusion time decay constant, (0.44-0.72) $\times 10^{-6} \mathrm{~s}^{-1}$ varied among samples. An example of the effects of these two parameters on radon build-up in the accumulation chamber is shown in Fig. 2, which shows the RAD7 readings (radon concentration) experimentally from a Red Indian granite sample plotted against elapsed time along with the build-up curve calculated with Eq. (3). Curve 1, in which both the leakage (L) and back diffusion (B) time decay constants were taken into account to determine the effective time decay constant $\left(\lambda_{\text {eff }}, \mathrm{s}^{-1}\right)$ shows good agreement with the experimental data. For Curve 2, only the back diffusion time decay constant was considered, and for Curve 3, the radon decay constant was assumed to be equal to the effective time decay constant (Eq. (1)).

Table 2 Radium equivalent index values and radon/thoron exhalation rates

\begin{tabular}{lccc}
\hline \multirow{2}{*}{ Sample ID } & $\begin{array}{c}\mathrm{Ra}_{\mathrm{eq}} \text { index } \\
\left(\mathrm{Bq} \mathrm{kg}^{-1}\right)\end{array}$ & \multicolumn{2}{c}{ Exhalation rate $\left(\mathrm{mBq} \mathrm{m}^{-2} \mathrm{~s}^{-1}\right)$} \\
\cline { 3 - 4 } & $193 \pm 5$ & $0.06 \pm 0.01$ & $76 \pm 34$ \\
\hline JGG-1 & $197 \pm 5$ & $0.47 \pm 0.04$ & $397 \pm 76$ \\
JGG-2 & $214 \pm 5$ & $0.18 \pm 0.01$ & $262 \pm 91$ \\
JGG-3 & $276 \pm 5$ & $0.81 \pm 0.06$ & $1535 \pm 199$ \\
JBG-1 & $297 \pm 5$ & $0.36 \pm 0.04$ & $2146 \pm 401$ \\
JBG-2 & $436 \pm 7$ & $0.25 \pm 0.02$ & $487 \pm 77$ \\
CGG-1 & $397 \pm 7$ & $0.33 \pm 0.01$ & $823 \pm 240$ \\
CBG-1 & $580 \pm 9$ & $0.19 \pm 0.01$ & $687 \pm 151$ \\
CBG-2 & $225 \pm 5$ & $0.10 \pm 0.01$ & $552 \pm 95$ \\
CRG-1 & $688 \pm 9$ & $1.04 \pm 0.03$ & $2420 \pm 667$ \\
IRG-1 & $720 \pm 11$ & $0.20 \pm 0.06$ & $1672 \pm 208$ \\
NGG-1 & $437 \pm 6$ & $0.12 \pm 0.01$ & $56 \pm 30$ \\
PGG-1 & $460 \pm 6$ & $0.08 \pm 0.01$ & $204 \pm 75$ \\
FBG-1 & $877 \pm 10$ & $0.93 \pm 0.07$ & $2267 \pm 364$ \\
FRG-1 & $465 \pm 8$ & $0.19 \pm 0.02$ & $515 \pm 86$ \\
BRG-1 & $431 \pm 209$ & $0.35 \pm 0.32$ & $940 \pm 834$ \\
\hline (mean \pm SD) & &
\end{tabular}

These results show that leakage and back diffusion greatly influenced the equilibrium radon concentration, indicating that the chamber leakage and back diffusion time decay constants should be calculated for accurate radon exhalation rate measurement by the accumulation method.

We thus estimated radon/thoron exhalation rates with Eq. (3), which takes into account the leakage and back diffusion time decay constants (Table 2). The exhalation rate ranged 


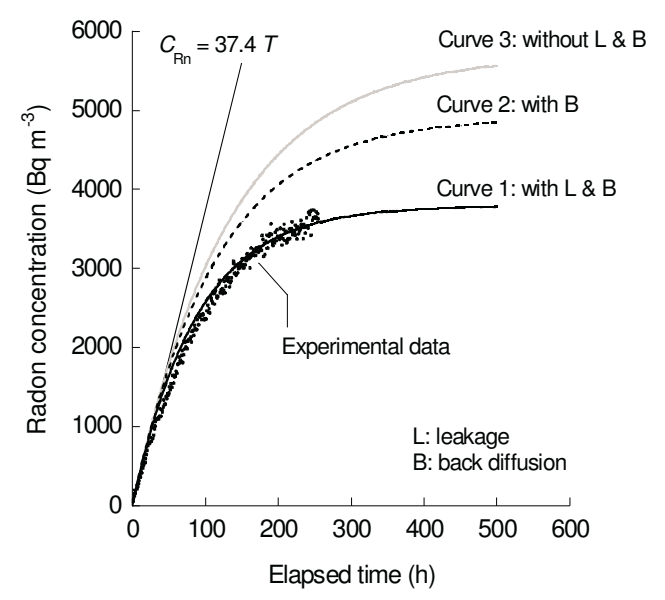

Fig. 2 Different build up curves for the same sample

from $0.06 \pm 0.01$ (JGG-1) to $1.04 \pm 0.03 \mathrm{mBq} \mathrm{m}^{-2} \mathrm{~s}^{-1}$ (IRG-1) with a mean value of $0.35 \pm 0.32 \mathrm{mBq} \mathrm{m}^{-2} \mathrm{~s}^{-1}$ for radon, and from $56 \pm 30$ (PGG-1) to $2420 \pm 667 \mathrm{mBq} \mathrm{m}^{-2} \mathrm{~s}^{-1}$ (IRG-1) with a mean of $940 \pm 834 \mathrm{mBq} \mathrm{m} \mathrm{s}^{-2}$ for thoron. We attributed the variation in radon/thoron exhalation rates to variations in radium/thorium concentrations, porosity, surface polishing and surface crystallography.

We observed a weak correlation between the radon
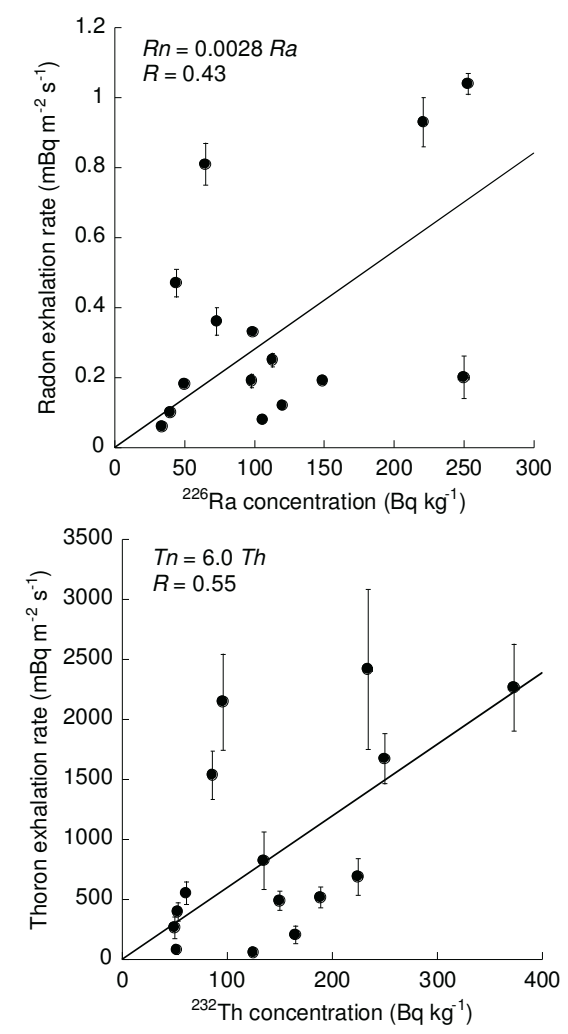

Fig. 3 Correlation between radon/thoron exhalation rates and parent radium/thorium nuclide concentrations exhalation rate and the radium concentration $(R=0.43)$, and between the thoron exhalation rate and the thorium concentration $(R=0.55)$ (Fig. 3). The weak correlation may reflect differences in the interior and surface structures of the grains and pore spaces. In addition to parent nuclide concentrations and grain structure, the emanation coefficient may influence exhalation rates. Exhalation rates may be low even with high concentrations of the parent nuclides are present if the emanation coefficient of the material has a low value.

\section{Conclusion}

We measured natural concentrations of the radionuclides ${ }^{226} \mathrm{Ra},{ }^{232} \mathrm{Th}$, and ${ }^{40} \mathrm{~K}$ in different kinds of granite building materials used in Japan with $\gamma$-ray spectroscopy and estimated the radium equivalent index using the resulting data. We also measured radon/thoron exhalation rates and determined their correlation with radium/thorium concentrations. On the basis of our results, we recommend that only the five Japanese granites and one Chinese granite (CRG-1) be used in construction. For safety, use of the other sampled building materials should be regulated from the viewpoint of radiation protection because the radium equivalent index values of these samples exceeded the international standard of $370 \mathrm{~Bq} \mathrm{~kg}^{-1}$.

\section{References}

1) UNSCEAR, United Nations Scientific Committee on the Effects of Atomic Radiation, "Sources and effects of ionizing radiation," New York, (2000).

2) J. A. Ademola, "Determination of natural radionuclides content in some building materials in Nigeria by gamma ray spectrometry," Health Phys., 94[1], 43 (2008).

3) S. Tokonami, M. Yang, H. Yonehara, et al., "Simple, discriminative measurement technique for radon and thoron concentrations with a single scintillation cell," Rev. Sci. Instrum., 73[1], 69 (2002).

4) M. Hosoda, M. Shimo, M. Sugino, et al., "Effect of soil moisture content on radon and thoron exhalation," J. Nucl. Sci. Technol., 44[4], 664 (2007).

5) S. Turhan, "Assessment of the natural radioactivity and radiological hazards in Turkish cement and its raw materials," J. Environ. Radioact., 99, 404 (2008).

6) P. Tuccimei, M. Moroni, D. Norcia, "Simultaneous determination of ${ }^{222} \mathrm{Rn}$ and ${ }^{220} \mathrm{Rn}$ exhalation rates from building materials used in Central Italy with accumulation chambers and a continuous solid state alpha detector: Influence of particle size, humidity and precursors concentration,” Appl. Radiat. Isot., 64, 254 (2006).

7) A. Poffijin, R. Bourgoingnie, R. Marijins, et al., "Laboratory measurements of radon exhalation and diffusion," Radiat. Prot. Dosim., 7[1-4], 77 (1984).

8) C. Y. Chao, T. C. Tung, D. Chan, et al., "Determination of radon emanation and back diffusion characteristics of building materials in small chamber tests," Build. Environ., 32 [4], 355 (1997) 